\title{
CONSUMO E DIGESTIBILIDADE APARENTE DO FENO DE Andropogon gayanus COLHIDO EM TRÊS IDADES DIFERENTES
}

\section{INTAKE AND APPARENT DIGESTIBILITY OF Andropogon gayanus HAY AT THREE DIFFERENT AGES}

\author{
André Cayô Cavalcanti $1^{1 *}$ \\ Eloísa de Oliveira Simões Saliba² \\ Lúcio Carlos Gonçalves ${ }^{2}$ \\ Norberto Mário Rodriguez ${ }^{2}$ \\ Iran Borges ${ }^{2}$ \\ Ana Luiza da Costa Cruz Borges² \\ ${ }^{1}$ Centro Universitário Norte do Espírito Santo, São Mateus, ES, Brasil \\ ${ }^{2}$ Universidade Federal de Minas Gerais, Belo Horizonte, MG, Brasil. \\ *Autor para correspondência - andrecavalcanti40@yahoo.com.br
}

\section{Resumo}

Este experimento teve como objetivo avaliar o consumo e a digestibilidade aparente da matéria seca, proteína bruta, frações fibrosas, energia e balanço do nitrogênio do feno de Andropogon gayanus colhido em três diferentes idades (56, 84 e 112 dias). O delineamento estatístico utilizado foi o inteiramente casualizado com três tratamentos e seis repetições. As digestibilidades aparentes da matéria seca, das frações fibrosas e da energia bruta foram maiores para os fenos colhidos aos $56 \mathrm{e}$ 84 dias $(\mathrm{P}<0,05)$. $\mathrm{O}$ feno de $A$. gayanus colhido aos 56 dias apresentou maiores valores de consumo e digestibilidade aparente da proteína bruta $(5,22 \mathrm{~g} / \mathrm{UTM} /$ dia; $55,69 \%$, respectivamente $)(\mathrm{P}<0,05)$ em relação aos demais tratamentos que não diferiram entre si ( $\mathrm{P}>0,05)$. Os valores de consumo e digestibilidade aparente apontam as idades de 56 e 84 dias como as melhores dentre as estudadas para o corte do capim A. gayanus para fenação.

Palavras-chave: forragem; ovino; valor nutritivo.

\begin{abstract}
The aim of this study was to evaluate the voluntary intake and apparent digestibility of dry matter, crude protein, fiber fractions, energy, and the nitrogen balance of Andropogon gayanus hay at three different stages (56, 84 and 112 days). The statistical design was completely randomized, with three treatments and six replicates. Dry matter, fiber fractions, and energy apparent digestibility were higher $(\mathrm{P}<0.05)$ for hay harvested at 56 and 84 days. Crude protein intake and apparent digestibility of $A$. gayanus hay harvested at 56 days of growth were greater $(\mathrm{P}<0.05)$ than the hay harvested at 84 and 112 days. The $A$. gayanus hay showed the best voluntary intake and digestibility at 56 and 84 days of age.
\end{abstract}

Keywords: forage; nutritive value; sheep.

Enviado em: 19 outubro 2011

Aceito em: 02 setembro 2016 


\section{Introdução}

As pastagens constituem a base da dieta dos ruminantes na grande maioria dos sistemas de produção brasileiros, devido às condições edafoclimáticas do nosso país favorecerem a produção de forrageiras tropicais. No Brasil existem aproximadamente 168 milhões de hectares de pastagens, dos quais cerca de 100 milhões são de pastagens cultivadas, sendo o restante de pastagens nativas ${ }^{(1)}$. Entre as forrageiras com maior área cultivada destacam-se as espécies dos gêneros Brachiaria, Panicum, Pennisetum, Cynodon e Andropogon. O capim Andropogon (Andropogon gayanus) destaca-se por sua alta produção de biomassa, capacidade de tolerar solos ácidos com baixa fertilidade e períodos de seca prolongados. Por esses motivos, este capim é considerado uma das gramíneas mais adaptadas a algumas regiões brasileiras sendo, atualmente, amplamente utilizado como pastagem cultivada, principalmente nas áreas de Cerrado.

Em consequência da sazonalidade climática, a disponibilidade de pastagem durante o ano é desuniforme em muitas regiões brasileiras, fazendo com que haja sempre um período de produção abundante de pastagem durante as águas e outro de escassez durante a seca. Além disso, o avanço da idade geralmente leva ao aumento dos teores de carboidratos estruturais e lignina, além de reduzir nutrientes potencialmente digestíveis da planta forrageira. Estes fatores tendem a influenciar negativamente o valor nutritivo, o consumo e a digestibilidade da forrageira, limitando a produção animal. Dessa forma, há necessidade constante de se avaliar nossas forrageiras manejando-as corretamente para, assim, se maximizar a eficiência de utilização destas na alimentação de ruminantes.

Uma alternativa viável para solucionar as flutuações de desempenho animal derivadas da sazonalidade climática e do avanço na idade da forrageira é a conservação de forragens na forma de feno. A técnica de fenação tem se destacado como uma técnica simples de se aplicar, que consiste em desidratar a forragem ao sol ou com o emprego de secadores artificiais, até que a mesma se apresente com teor de matéria seca (MS) superior a $80 \%$, para, desta forma, não sofrer problemas por ocasião do armazenamento.

Com a maturidade da planta, ocorre redução proporcional de folhas, o que resulta em fenos de menor valor nutritivo, mas com maior produção por área. Assim, o sucesso de um feno com boa qualidade está na adequada escolha do momento de corte, conciliando valor nutritivo e produção, já que em idade tenra a produtividade é menor.

Apesar de o capim Andropogon ter sido introduzido e difundido há mais de 30 anos no território brasileiro, pouco se sabe sobre seu rendimento, consumo voluntário, digestibilidade aparente e valor nutritivo, quando armazenado na forma de feno. Dessa forma, objetivou-se com este trabalho avaliar o valor nutritivo do feno do capim Andropogon gayanus colhido em três diferentes idades, por meio do consumo voluntário e digestibilidade aparente em ovinos.

\section{Material e Métodos}

O feno foi produzido em uma fazenda localizada no município de Lagoa Santa, Minas Gerais, situada a 19³5'36" de latitude Sul e 43051'56" de longitude Oeste de Greenwich, com altitude média de 747 metros. Foi utilizada uma área de capim Andropogon gayanus já estabelecida. Na análise de solo observaram-se as seguintes características: $\mathrm{pH} 5,3, \mathrm{Al}^{3+} 0,6 \mathrm{cmol}$ carga $/ \mathrm{dm}^{3}, \mathrm{P} 1,5 \mathrm{mg} / \mathrm{dm}^{3}, \mathrm{~K} 183 \mathrm{mg} /$ $\mathrm{dm}^{3}$, índice de saturação de bases de $39 \%$ e classificação de textura franco argilosa. Com base na análise de solo, no início do período chuvoso, procedeu-se a correção da acidez com a aplicação de $2000 \mathrm{~kg} /$ ha de calcário dolomítico. Trinta dias depois, foi realizada a uniformização da área experimental, a 20 $\mathrm{cm}$ do solo com o uso de roçadeira movida pela tomada de força do trator e a adubação. Para adubação de cobertura foram utilizados $250 \mathrm{~kg} / \mathrm{ha}$ de $08-24-12$ e $100 \mathrm{~kg} / \mathrm{ha}$ de 30-00-20 (N:P:K). O capim foi submetido ao corte em três épocas ( 3 tratamentos), nas seguintes idades de crescimento: 56,84 e 112 
dias. O primeiro corte foi realizado dia 27 de janeiro de 2007 e os demais a cada 28 dias.

A confecção dos fenos foi realizada na Escola de Veterinária da Universidade Federal de Minas Gerais. A forragem foi cortada anteriormente e colocada em bandejas de ferro de $1 \mathrm{~m}^{2}(1 \mathrm{x} 1 \mathrm{~m})$, em camadas de $5 \mathrm{~cm}$ e expostas ao sol, sendo reviradas quatro vezes ao dia. Caso não dessem ponto de feno, as bandejas eram recolhidas e colocadas em galpão, para evitar o orvalho, e no dia seguinte eram expostas novamente ao sol. O ponto de feno era observado quando, ao torcer um molho de folhas e hastes, apenas algumas se rompiam.

Foram utilizados dezoito carneiros adultos, sadios, sem raça definida, com peso médio de $37 \mathrm{~kg}$ para avaliação da digestibilidade aparente dos nutrientes. Os animais foram pesados no início e no final do período experimental, previamente vermifugados, vacinados e alojados em gaiolas metabólicas individuais, confeccionadas em cantoneira de ferro e piso ripado de madeira, com bebedouro e comedouro de aço inoxidável e saleiro de polietileno. Nos baldes coletores de urina foram adicionados, diariamente, $100 \mathrm{ml}$ de $\mathrm{HCl} 2 \mathrm{~N}$ para evitar perda de nitrogênio por volatilização e decomposição.

Seis animais para cada tratamento foram sorteados aleatoriamente, passando então por um período inicial de adaptação às gaiolas e alimentação de 21 dias, seguido de um período de coleta de amostras de cinco dias. O feno foi oferecido em quantidade suficiente para que se obtivessem aproximadamente $10 \%$ de sobras no cocho. A água e a mistura mineral comercial foram administradas à vontade. Diariamente foram mensuradas as quantidades de feno (oferecidos e sobras) e, no período de coleta, as produções de fezes e urina de cada animal.

Para os fenos oferecidos foram coletados aproximadamente $300 \mathrm{~g}$ por tratamento por dia. As sobras foram recolhidas, pesadas e armazenadas por animal diariamente. Já as fezes foram pesadas e amostradas ( $20 \%$ do peso total diário), assim como a urina (10\% do volume total).

As amostras do dia (oferecido, sobras, fezes e urina), após devidamente identificadas, foram armazenadas em câmara fria à temperatura de $-17^{\circ} \mathrm{C}$. Ao fim do período experimental, foram feitas amostras compostas por animal de sobras, fezes e urina que permaneceram estocadas a $-17^{\circ} \mathrm{C}$ até a manipulação para análise laboratorial.

Cada amostra composta foi descongelada sob temperatura ambiente, procedendo-se a pré-secagem à $55{ }^{\circ} \mathrm{C}$ por 72 horas e, posteriormente, a moagem em moinho estacionário, com peneira de $1,0 \mathrm{~mm}$. Nas amostras dos fenos, sobras e fezes foram realizadas as análises de matéria seca em estufa à $105^{\circ} \mathrm{C}$ (MS), proteína bruta (PB) pelo método MacroKjedahl e extrato etéreo (EE) segundo Detmann et al. ${ }^{(2)}$, fibra em detergente neutro (FDN), fibra em detergente ácido (FDA), lignina, nitrogênio insolúvel em detergente neutro (NIDN), nitrogênio insolúvel em detergente ácido (NIDA), segundo Licitra et al. ${ }^{(3)}$, e energia bruta (EB) por combustão em bomba calorimétrica adiabática modelo IKA Works C $2000^{(2)}$. Nas amostras dos fenos realizou-se ainda a digestibilidade in vitro da matéria seca (DIVMS) segundo Tilley e Terry ${ }^{(4)}$. As amostras de urina foram analisadas para determinação dos teores de energia bruta e nitrogênio total seguindo metodologias já mencionadas.

Utilizou-se um delineamento inteiramente casualizado, com três tratamentos e seis repetições por tratamento. Para a comparação das médias dos tratamentos foi utilizado o teste $\mathrm{SNK}(\mathrm{P}<0,05)$.

\section{Resultados e Discussão}

Verificou-se que os teores de matéria seca (MS) dos fenos aumentaram com o avanço da idade de corte do capim Andropogon gayanus (Tabela 1). Resultado semelhante a este foi verificado por Moreira et al. ${ }^{(5)}$, que trabalhou com feno de capim Andropogon colhido em quatro diferentes idades $(56,84,112$ e 140 dias), sendo o valor mínimo observado para o feno colhido aos 56 dias com $91,3 \%$ de MS e o valor máximo para o feno colhido aos 140 dias com valor de 92,3\% de MS. Segundo Ataíde Júnior et al. ${ }^{(6)}$, fenos são produzidos a partir de forragens verdes desidratadas com umidade inferior a $20 \%$, o que permite que sejam armazenados, desde que adequadamente, sem deterioração de seus princípios 
nutritivos. Portanto, os fenos avaliados nesta pesquisa, apresentaram teores adequados de MS, o que permite que sejam armazenados e não percam valor nutritivo.

Com o avanço do estádio de maturidade da forrageira, foi observada diminuição do teor de proteína bruta (PB) nos fenos produzidos (Tabela 1). Observou-se que somente os fenos das plantas cortadas nos intervalos de 56 e 85 dias apresentaram concentrações superiores a 6\%, o que, segundo Bohnert et al. ${ }^{(7)}$, é a concentração mínima para manutenção adequada da microbiota ruminal. Esses resultados concordam com Ribeiro Júnior et al. ${ }^{(8)}$ que, trabalhando com silagens da gramínea A. gayanus cv. Planaltina colhida aos 56, 84 e 112 dias, observaram diminuição do teor de PB ao longo do tempo com valores de 7,86; 6,28 e $5,32 \%$, respectivamente.

Tabela 1. Valor nutritivo do feno de capim Andropogon gayanus colhido em diferentes idades de crescimento

\begin{tabular}{lccc}
\hline & \multicolumn{3}{c}{ Idade (dias) } \\
\hline Matéria seca (\%) & $\mathbf{5 6}$ & $\mathbf{8 4}$ & $\mathbf{1 1 2}$ \\
Proteína Bruta (\%MS) & 81,69 & 85,67 & 87,55 \\
Fibra em detergente neutro (\%MS) & 7,27 & 6,12 & 4,71 \\
Fibra em detergente ácido (\%MS) & 71,10 & 73,62 & 75,54 \\
Lignina (\%MS) & 42,15 & 43,32 & 45,61 \\
$\mathrm{NIDN}^{1}(\% \mathrm{~N}$ total) & 5,25 & 6,08 & 6,23 \\
$\mathrm{NIDA}^{2} /(\% \mathrm{~N}$ total) & 30,40 & 41,12 & 42,12 \\
Digestibilidade in vitro da MS (\%) & 17,01 & 20,18 & 24,70 \\
Energia Bruta (Mcal/kg) & 61,93 & 56,34 & 48,06 \\
\hline
\end{tabular}

${ }^{1}$ Nitrogênio insolúvel em detergente neutro; ${ }^{2}$ Nitrogênio insolúvel em detergente ácido.

Os valores de nitrogênio insolúvel em detergente neutro (NIDN) e nitrogênio insolúvel em detergente ácido (NIDA) obtidos para o feno de A. gayanus nas diferentes idades sofreram aumento com o avanço da idade de corte. Considerando-se que a fração NIDA não é degradada pelas bactérias ruminais bem como não fornece aminoácidos pós-ruminalmente e alta percentagem da fração NIDN escapa da degradação no rúmen ${ }^{(9)}$, o teor de proteína bruta da forragem passa a ser mais limitante com o avanço da idade de corte já que parte da proteína torna-se pouco disponível ou indisponível aos microrganismos ruminais e ao animal.

A fibra em detergente neutro (FDN) e a fibra em detergente ácido (FDA) aumentaram com a idade de corte do Andropogon na confecção dos fenos. Como o FDN, segundo Jung e Allen ${ }^{(10)}$, está relacionada ao consumo voluntário e o FDA está relacionado a alterações na digestibilidade ${ }^{(3)}$, provavelmente os fenos do A. gayanus colhidos nas idades mais avançadas serão menos consumidos e degradados.

Os teores de FDN e de FDA observados nas idades de 56, 84 e 112 dias foram numericamente próximos ao observado por Bueno et $\mathrm{al}^{(11)}$, que trabalhou com o capim Andropogon nessas mesmas idades e encontrou valores de 72,$9 ; 74,3,73,9 \%$ e 42,$4 ; 44,9,44,6 \%$, respectivamente.

A concentração de lignina (LIG) aumentou nos fenos produzidos com A. gayanus com o avançar da idade de colheita. Como a LIG afeta a digestibilidade dos componentes da parede celular e esse efeito é mais pronunciado com o avançar da idade das forrageiras ${ }^{(12)}$, provavelmente os fenos produzidos com a forragem colhida nos estádios mais avançados serão menos degradados. Os teores de LIG encontrados foram superiores àqueles observados por Ribeiro Júnior et al. ${ }^{(8)}$, que trabalharam com silagens de capim A. gayanus nas mesmas idades deste estudo e encontraram valores variando de 3,6 a 4,5\%.

A DIVMS diminuiu com o avançar da idade de colheita da forragem. Este fato provavelmente relacionase às observações entre a DIVMS com os teores dos componentes da parede celular FDN, FDA e LIG como apresentado na Tabela 1. Os resultados obtidos estão de acordo com a literatura, a qual cita que o aumento dos componentes da parede celular reduz sua degradabilidade pelos ruminantes ${ }^{(6,13,14)}$. 
Tabela 2. Consumo de nutrientes e valores de energia digestível do feno de $A$. gayanus colhido em diferentes idades de crescimento

\begin{tabular}{lccc}
\hline & \multicolumn{3}{c}{ Idade (dias) } \\
& $\mathbf{5 6}$ & $\mathbf{8 4}$ & $\mathbf{1 1 2}$ \\
\hline CMSPM (g/UTM/dia) & $71,32^{\mathrm{a}}$ & $71,28^{\mathrm{a}}$ & $58,02^{\mathrm{b}}$ \\
DAMS (\%) & $60,79^{\mathrm{a}}$ & $54,06^{\mathrm{a}}$ & $45,26^{\mathrm{b}}$ \\
CPBPM (g/UTM/dia) & $5,22^{\mathrm{a}}$ & $3,71^{\mathrm{b}}$ & $2,78^{\mathrm{c}}$ \\
DAPB (\%) & $55,69^{\mathrm{a}}$ & $41,1^{\mathrm{b}}$ & $26,99^{\mathrm{c}}$ \\
CEBPM (Kcal/UTM/dia) & 293,58 & 301,58 & 254,92 \\
DAEB (\%) & $62,56^{\mathrm{a}}$ & $58,65^{\mathrm{a}}$ & $48,91^{\mathrm{b}}$ \\
CEDPM (Kcal/UTM/dia) & 182,03 & 168,77 & 125,26 \\
ED (Mcal/Kg) & $2,59^{\mathrm{a}}$ & $2,35^{\mathrm{a}}$ & $1,90^{\mathrm{b}}$ \\
\hline
\end{tabular}

Médias seguidas por letras minúsculas idênticas significam semelhança estatística em uma mesma linha $(\mathrm{P}>0,05)$ pelo teste SNK. CMSPM = consumo de matéria seca por unidade de peso metabólico; $\mathrm{CPBPM}=$ consumo de proteína bruta por unidade de peso metabólico; CEBPM = consumo de energia bruta por unidade de peso metabólico; CEDPM = consumo de energia digestível por unidade de peso metabólico; DAMS = digestibilidade aparente da matéria seca; DAPB = digestibilidade aparente da proteína bruta; DAEB = digestibilidade aparente da energia bruta.

Os valores de consumo de matéria seca por unidade de tamanho metabólico (CMSPM) do feno do capim Andropogon colhido aos 56 e 84 dias foram semelhantes entre si $(P>0,05)$ e superiores $(P<0,05)$ ao colhido na idade de 112 dias (Tabela 2).

O consumo médio de MS dos fenos foi de 66,9 g/UTM/dia, valor próximo aos descritos para ovinos adultos em mantença pelo NRC ${ }^{(15)}$ e AFRC ${ }^{(16)}$, que são de 63,19 e 61,02 g/UTM/dia, respectivamente.

Assim como ocorreu no CMSPM, a digestibilidade aparente da matéria seca (DAMS) também sofreu influência da idade de corte. Segundo Minson e Milford ${ }^{(17)}$, Mathis et al. ${ }^{(18)}$ e Bohnert et al..$^{(7)}$, teores de proteína bruta da dieta inferiores a $6 \%$ podem limitar o crescimento microbiano no rúmen, o que resulta em redução da digestibilidade da dieta, fato este evidenciado neste trabalho. Além disso, segundo Wilson e Hatfield ${ }^{(12)}$, com o avanço da maturidade da planta, normalmente ocorre diminuição da relação folha/ haste. As hastes apresentam em sua composição tecidos vegetais de menor taxa de degradação ruminal (esclerênquima e xilema) $^{(12)}$. Estes são tecidos vegetais de sustentação e vasculares, que possuem células densamente agrupadas com paredes espessas e lignificadas, de difícil degradação pelos microorganismos do rúmen ${ }^{(19)}$. Dessa forma, o aumento da proporção de hastes na planta mais velha poderia também afetar a DAMS. Embora o avanço da maturidade da planta também possa causar redução na digestibilidade das folhas das gramíneas, este efeito é muito menor do que o observado nas hastes ${ }^{(10,19)}$.

O consumo de proteína bruta em gramas por unidade de tamanho metabólico (CPBPM) e a digestibilidade aparente da proteína bruta (DAPB) do feno colhido aos 56 dias de idade foi superior $(\mathrm{P}<0,05)$ ao colhido aos 84 dias, sendo este superior $(\mathrm{P}<0,05)$ ao colhido aos 112 dias (Tabela 2).

A redução na DAPB associada ao aumento da maturidade da planta é consistente com os resultados de diversos trabalhos avaliando gramíneas forrageiras $\mathrm{C} 3$ e $C 4^{(8,19,21-23)}$. Esta redução da digestibilidade da $\mathrm{PB}$ parece estar relacionada à redução da solubilidade do nitrogênio e ao aumento da fração nitrogenada associada à parede celular e ligada a lignina ${ }^{(3,12)}$.

Os baixos teores de PB (inferiores a 6\% da MS) e/ou disponibilidade desta no alimento podem limitar a fermentação ruminal reduzindo a digestibilidade da $\mathrm{MS}^{(3,17)}$. De acordo Satter e Slyter ${ }^{(24)}$, o crescimento das bactérias celulolíticas foi limitado quando as concentrações de nitrogênio amoniacal no líquido ruminal foram inferiores a $5 \mathrm{mg} / 100 \mathrm{ml}$, indicando que a baixa disponibilidade de proteína degradável no rúmen pode estar limitando a degradação do alimento, o que pode ocorrer principalmente no feno colhido aos 112 dias de idade.

Não foram observadas diferenças no consumo de energia bruta (CEBPM) e no consumo de energia 
digestível por unidade de tamanho metabólico. Para a energia digestível (ED), os fenos colhidos aos 56 e 84 dias foram semelhantes $(\mathrm{P}>0,05)$ entre si e superiores $(\mathrm{P}<0,05)$ ao feno colhido aos 112 dias (Tabela 2).

De acordo com $\mathrm{NRC}^{(15)}$, a exigência de energia digestível para ovinos em mantença é de 146,5 kcal/ UTM/dia. Os fenos produzidos aos 56 e 84 dias foram capazes de suprir esta exigência. Entretanto, os animais alimentados com o feno produzido aos 112 dias de rebrote com um CEDPM de 125,6 kcal/ UTM/dia apresentaram retenção de energia positiva o que indica que a demanda de energia digestível para mantença dos animais deste experimento pode ter sido mais baixa que a descrita pelo $\mathrm{NRC}^{(15)}$.

A redução do valor de energia digestível com o aumento da idade deve-se provavelmente à redução do conteúdo celular e aumento das frações fibrosas FDN e FDA de menor digestibilidade. Este fato demonstra a importância de se melhorar a digestibilidade da fração fibrosa para se conseguir um melhor consumo e aproveitamento da energia pelos animais alimentados com estes fenos. Além disso, indica que o consumo de energia foi provavelmente limitado pela capacidade física do rúmen, ou seja, à medida que a digestibilidade da fração fibrosa aumenta, o CEDPM aumenta.

Tabela 3. Balanço de Nitrogênio em ovinos alimentados com fenos de A. gayanus colhido em diferentes idades de crescimento

\begin{tabular}{lccc}
\hline & \multicolumn{3}{c}{ Idade (dias) } \\
& $\mathbf{5 6}$ & $\mathbf{8 4}$ & $\mathbf{1 1 2}$ \\
\hline $\mathrm{NC}(\mathrm{g} /$ dia $)$ & $12,88^{\mathrm{a}}$ & $8,62^{\mathrm{b}}$ & $7,57^{\mathrm{b}}$ \\
$\mathrm{NF}(\mathrm{g} / \mathrm{dia})$ & 5,34 & 4,32 & 4,65 \\
$\mathrm{NU}(\mathrm{g} /$ dia $)$ & $2,36^{\mathrm{a}}$ & $0,91^{\mathrm{b}}$ & $0,85^{\mathrm{b}}$ \\
$\mathrm{NR}(\mathrm{g} /$ dia $)$ & $5,76^{\mathrm{a}}$ & $2,96^{\mathrm{b}}$ & $2,01^{\mathrm{b}}$ \\
$\mathrm{NR} / \mathrm{NC}-\mathrm{NF})(\mathrm{g} /$ dia $)$ & 76,33 & 68,85 & 68,83 \\
$\mathrm{NR} / \mathrm{NC}(\%)$ & $44,72^{\mathrm{a}}$ & $34,33^{\mathrm{b}}$ & $26,55^{\mathrm{b}}$ \\
$\mathrm{BN}$ & $5,18^{\mathrm{a}}$ & $3,39^{\mathrm{b}}$ & $2,07^{\mathrm{b}}$ \\
\hline
\end{tabular}

Médias seguidas por letras minúsculas idênticas significam semelhança estatística em uma mesma linha $(\mathrm{P}>0,05)$ pelo teste SNK. NC = nitrogênio consumido; $\mathrm{NF}=$ nitrogênio fecal; $\mathrm{NU}=$ nitrogênio urinário; $\mathrm{NR}=$ nitrogênio retido; $\mathrm{NR} / \mathrm{NC}=$ nitrogênio retido/nitrogênio consumido; $\mathrm{NR} /(\mathrm{NC}-\mathrm{NF})$ = eficiência de retenção do nitrogênio; $\mathrm{BN}=$ balanço de nitrogênio.

Apesar do baixo consumo de $\mathrm{PB}$, os animais apresentaram balanço de nitrogênio (BN) positivo (Tabela 3). Na tentativa de compensar um menor consumo de $\mathrm{N}(\mathrm{P}<0,05)$, os animais alimentados com os fenos em idades mais avançadas reduziram $(\mathrm{P}<0,05)$ a excreção de $\mathrm{N}$ na urina. Já o nitrogênio fecal (NF) e a eficiência de utilização do nitrogênio ( $\mathrm{N}$ retido/( $\mathrm{N}$ ingerido - $\mathrm{N}$ fecal)) não variaram $(\mathrm{P}>0.05)$ entre os animais alimentados com os fenos confeccionados em diferentes idades de corte. Deve-se levar em consideração que as perdas de NF são em grande parte influenciadas pelo nitrogênio de origem endógena.

Moreira et al. ${ }^{(25)}$ avaliaram o BN em dietas de ovinos com feno de capim coast-cross colhido aos 56 dias de crescimento, encontrando valores de $0,58,3,15,5,30 \mathrm{~g}$ /dia de NU, NF e NC, respectivamente, e relação de NR/NC de 53,0\%, valores estes superiores aos encontrados no presente trabalho com o feno colhido na mesma idade.

Lima et al. ${ }^{(20)}$, trabalhando com feno de capim arroz (Echinochloa sp.), também observaram redução da excreção urinária de nitrogênio com o aumento da idade de corte do capim. De acordo com Licitra et al. ${ }^{(3)}$, a baixa ingestão de nitrogênio leva à redução da excreção de ureia na urina para manutenção do pool de ureia plasmático.

O BN pode ser indicativo do metabolismo proteico animal, sendo mais eficiente que a digestibilidade e o consumo de proteína para evidenciar se há perda ou não de proteínas pelo organismo ${ }^{(15)}$. Entretanto, parece não ser um bom indicativo de níveis adequados de nitrogênio para uma eficiente fermentação 
ruminal. De acordo com Lima et al.(20), mesmo apresentando BN positivos, as concentrações de nitrogênio amoniacal no líquido ruminal de ovinos alimentados com feno de capim arroz foram inferiores a $5 \mathrm{mg} / 100 \mathrm{ml}$, o que de acordo Satter e Slyter ${ }^{(24)}$ limitaria o crescimento das bactérias celulolíticas e, consequentemente, a digestão da fibra. O papel do nitrogênio reciclado no rúmen pode ser quantitativamente importante quando dietas com baixa concentração de proteínas são fornecidas aos animais. De acordo com o NRC ${ }^{(15)}$, animais alimentados com dietas contendo $5 \%$ de proteína bruta reciclam $70 \%$ da proteína ingerida, fato este evidenciado no presente trabalho.

Tabela 4. Consumo e digestibilidade das frações fibrosas em ovinos alimentados com fenos de A. gayamus colhido em diferentes idades de crescimento

\begin{tabular}{lccc}
\hline & \multicolumn{3}{c}{ Idade (dias) } \\
& $\mathbf{5 6}$ & $\mathbf{8 4}$ & $\mathbf{1 1 2}$ \\
\hline CFDNPM (g/UTM/dia) & 50,87 & 52,6 & 44,13 \\
DAFDN (\%) & $63,27^{\mathrm{a}}$ & $59,97^{\mathrm{a}}$ & $51,00^{\mathrm{b}}$ \\
CFDAPM (g/UTM/dia) & 32,9 & 32,51 & 26,2 \\
DAFDA (\%) & $59,17^{\mathrm{a}}$ & $55,45^{\mathrm{a}}$ & $47,91^{\mathrm{b}}$ \\
CLIGPM (g/UTM/dia) & $4,55^{\mathrm{a}}$ & $4,47^{\mathrm{a}}$ & $3,64^{\mathrm{b}}$ \\
\hline
\end{tabular}

Médias seguidas por letras maiúsculas idênticas significam semelhança estatística em uma mesma linha $(\mathrm{P}>0,05)$ pelo teste SNK. CFDNPM = consumo de fibra em detergente neutro por unidade de tamanho metabólico; DAFDN = digestibilidade aparente da fibra em detergente neutro; CFDAPM = consumo de fibra em detergente ácido por unidade de peso metabólico; DAFDA = digestibilidade aparente da fibra em detergente ácido; CLIGPM = consumo de lignina por unidade de tamanho metabólico.

Os consumos de fibra em detergente neutro (CFDNPM) e fibra em detergente ácido por unidade de tamanho metabólico (CFDAPM) não diferiram $(\mathrm{P}>0,05)$ entre os fenos colhidos nas diferentes idades de corte do capim Andropogon (Tabela 4). Já as digestibilidades aparentes da fibra em detergente neutro (DAFDN) e da fibra em detergente ácido (DAFDA) dos fenos colhidos aos 56 e 84 dias foram superiores ao feno colhido aos 112 dias.

Ribeiro Júnior et al. ${ }^{(8)}$ observou valores semelhantes de consumos de FDN para silagens de $A$. gayanus (entre 40,6 e 52,8 g/UTM/dia) produzidos nas mesmas idades de corte deste trabalho.

O consumo médio de FDN observado neste trabalho foi de 49,2 g/UTM/dia, sendo superior aos 35 $\mathrm{g} / \mathrm{UTM} /$ dia para forragens com teores de FDN entre $35 \%$ e $75 \%$ proposto por Wilson e Hatfield ${ }^{(12)}$ para ovinos. Mesmo com o feno colhido aos 112 dias apresentando diferenças entre os colhidos aos 56 e 84 dias nas digestibilidades da MS, FDN e FDA, os animais tentaram compensar estes quesitos consumindo o máximo possível de feno na tentativa de suprir sua demanda energética. Dessa forma, a quantidade de FDN consumida parece ter sido um dos fatores responsáveis pela regulação do consumo de matéria seca deste experimento, o que está de acordo com a observação de Conrad et al. ${ }^{(26)}$ de que, para forragens com digestibilidade da matéria seca abaixo de $66,7 \%$, o fator físico de enchimento ruminal exerce maior influência sobre o consumo voluntário.

Várias características químicas e estruturais que limitam a digestão da fibra já foram identificadas. Destas, a lignina se destaca como o principal e mais mencionado componente limitador da digestão dos polissacarídeos da parede celular no rúmen ${ }^{(10)}$. De acordo com Buxton e Russell(27) e Jung e Allen ${ }^{(10)}$, a mudança na composição das ligninas de guaiacila para siringila e o aumento das ligações cruzadas entre a lignina e as hemiceluloses intermediadas pelo ácido ferúlico com a maturação da planta podem ser mais importantes na redução na digestibilidade da fibra que a concentração de lignina na planta. Muito embora isto possa acontecer, teores de PB muito baixos $(<6 \%)$ como no feno colhido aos 112 dias parece ser uma explicação mais plausível para esta redução na digestibilidade da fração fibrosa. 


\section{Conclusões}

Os valores de consumo voluntário e os teores de digestibilidade aparente apontam as idades de 56 e 84 dias como as melhores dentre as estudadas para o corte do capim Andropogon gayanus destinado à confecção de feno.

\section{Referências}

1. IBGE - Instituto Brasileiro de Geografia e Estatística. Censo Agropecuário. 2011. Acesso em 02 de março de 2016. Disponível em http://www.ibge.gov.br/home/estatística/economia/ppm/2014/default.shtm.

2. Detmann E, Souza MA, Valadares Filho SC. Métodos para análise de alimentos. Visconde do Rio Branco: Universidade Federal de Viçosa, 2012; 214.

3. Licitra G, Hernandez TM, Van Soest PJ. Standardization of procedures for nitrogen fractionation of ruminant feeds. Animal Feed Science and Technology. 1996; 57(1):347-358. http://www.sciencedirect.com/science/ article/pii/0377840195008373

4.Tilley JMA, Terry RA. A two stage technique for the in vitro digestion of forage crops. Journal of the British Grassland Society. Hurley. 1963; 18(2):104-111. http://onlinelibrary.wiley.com/doi/10.1111/j.1365-2494.1963. tb00335.x/abstract

5.Moreira GR, Saliba EOS, Gonçalves LC, Mauricio RM, Sousa LF, Rodriguez NM, Lana AMQ. Avaliação nutricional de fenos produzidos com Andropogon gayanus cv. Planaltina. Arquivo Brasileiro de Medicina Veterinária e Zootecnia. 2013; 65(1):865-873. http://www.scielo.br/scielo.php?script=sci arttext\&pid=S0102-09352013000300036

6.Ataíde Júnior JR, Pereira OG, Valadares Filho SC, Garcia R, Cecon PR, Alves MJ, Moreira AL. Consumo, Digestibilidade e Desempenho de Novilhos Alimentados com Rações à Base de Feno de Capim-Tifton 85, em Diferentes Idades de Rebrota. Revista Brasileira de Zootecnia. 2010; 30(1):215 - 222. http://www.scielo.br/ $\mathrm{pdf} / \mathrm{rbz} / \mathrm{v} 30 \mathrm{n} 1 / 5455 . \mathrm{pdf}$

7. Bohnert DW, Delcurto T, Clark AA. Protein supplementation of ruminants consuming low-quality cool- or warm-season forage: Differences in intake and digestibility. Journal of Animal Science, 2011. 89(1):37073717. http://www.ncbi.nlm.nih.gov/pubmed/21622884

8. Ribeiro Júnior GO, Velasco FO, Faria Junior WG, Teixeira AM, Machado FS, Magalhães FA, Jayme DG, Gonçalves LC. Cinética de degradação in situ das silagens de capim Andropogon gayanus produzidas em três idades de corte. Arquivo Brasileiro de Medicina Veterinária e Zootecnia. 2014; 66(1):1883-1890. http:// www.scielo.br/pdf/abmvz/v66n6/0102-0935-abmvz-66-06-01883.pdf

9. Sniffen CJ, O'connor JD, Van Soest PJ. A net carbohydrate and protein system for evaluating cattle diets. II. Carbohydrate and protein availability. Journal of Animal Science, 1992; 70(7):3562-3577. http://www.ncbi. nlm.nih.gov/pubmed/1459919

10. Jung, HJG, Allen MS. Characteristics of plant cell wall affecting intake and digestibility of forages by ruminants. Journal Animal Science, 1995; 73(1):2774-2790. http://www.ncbi.nlm.nih.gov/pubmed/8582870

11. Bueno ICS, Vitti DMSS, Abdalla AL, Louvandini H. Consumo voluntário, digestibilidade aparente e cinética digestiva de três forrageiras em ovinos. Ciência Animal Brasileira. 2007; 8(4):713 - 722. http://www. revistas.ufg.br/vet/article/view/2692

12. Wilson JR, Hatfield RD. Structural and chemical changes of cell wall types during stem development: consequences for fibre degradation by rumen microflora. Australian Journal of Agricultural Research. 1997; 48(1):165-180. http://www.publish.csiro.au/paper/A96051.htm

13. Deschamps FC. Implicações do período de crescimento na composição química e digestão dos tecidos de 
cultivares de capim elefante. Revista Brasileira de Zootecnia. 1999; 28(6):1178-1189. http://www.scielo.br/ $\mathrm{pdf} / \mathrm{rbz} / \mathrm{v} 28 \mathrm{n} 6 / \mathrm{a} 25 \mathrm{v} 28 \mathrm{n} 6 . \mathrm{pdf}$

14. Alves de Brito CJF, Rodella RA, Deschamps FC. Perfil Químico da Parede Celular e suas Implicações na Digestibilidade de Brachiaria brizantha e Brachiaria humidicola. Revista Brasileira de Zootecnia. 2005; 32(6):1835-1844. http://www.scielo.br/scielo.php?script=sci arttext\&pid=S1516-35982003000800005

15. National Research Council - NRC. Nutrient requirements of small ruminants. 2007; 362. http://www.aces. edu/pubs/docs/A/ANR-0812/ANR-0812.pdf

16. Agricultural And Food Research Council - AFRC: Energy and protein requirements of ruminants. Wallingford: CAB International. 1993; 159. http://books.google.com.br/

17. Minson DJ, Milford R. The voluntary intake and digestibility of diets containing different proportions of legume and mature Pangola grass (Digitaria decumbens). Australian Journal of Experimental Agriculture and Animal Husbandry. 1967; 7(29):546-551. http://www.publish.csiro.au/paper/EA9670546.htm

18. Mathis CP, Cochran RC, Heldt JS. Effects of supplemental degradable intake protein on utilization of medium- to low-quality forages. Journal of Animal Science. 2000; 78(1):224-232. http://www.ncbi.nlm.nih. gov/pubmed/10682825

19. Archiméde H, Eugéne M, Mariemagdeleine C. Comparison of methane production between $\mathrm{C} 3$ and $\mathrm{C} 4$ grasses and Legumes. Animal Feed Science Technology. 2011; 166(167):59-64. http://www.sciencedirect. com/science/article/pii/S0377840111001222

20. Lima LD, Kozloski GV, Sanchez LMB. Effect of harvesting period on the nutritive value of rice grass (Echinochloa sp.) hay given as sole diet to lambs. Small Ruminant Research. 2008; 75(1):217-225. http:// www.sciencedirect.com/science/article/pii/S0921448807002659

21.Vranic M, Knezevic M, Perculija G. Intake, digestibility in vivo, utilization and in sacco dry matter degradability of grass silage harvested at three stages of maturity. Asian-Australasian Journal of Animal Science. 2009; 22(2):225-231. http://www.ajas.info/journal/view.php?number=22018

22.Castro GHF, Rodriguez NM, Gonçalves LC, Mauricio RM. Características produtivas, agronômicas e nutricionais do capim-tanzânia em cinco diferentes idades ao corte. Arquivo Brasileiro de Medicina Veterinária e Zootecnia. 2010; 62(1):654-666. http://www.scielo.br/scielo.php?pid=S010209352010000300022\&script=sci_abstract\&tlng=pt

23. Teixeira AM, Gonçalves LC, Velasco FO, Ribeiro Junior GO, Faria Junior WG, Cruz DSG, Jayme DG. Respirometria e emissão de metano por ovinos alimentados com Capim-elefante cortado com diferentes idades. Bioscience Journal (Online). 2015; 31(1):841-849. http://www.seer.ufu.br/index.php/biosciencejournal/article/ viewFile/22577/16475

24. Satter LD, Slyter LL. Effect of ammonia concentration on rumen microbial production in vitro. British Journal of Nutrition. 1974; 32(2):199-208. http://journals.cambridge.org/action/ displayAbstract? fromPage $=$ online $\&$ aid $=1225544 \&$ fileId $=$ S0007114574000742

25. Moreira AL, Lima GFC, Santos MVFS, Carvalho FFR, Medeiros HR, Maciel FC, Januário ACC. Consumo e digestibilidade aparente da silagem de milho e dos fenos de alfafa e capim coast - cross, em ovinos. Revista Brasileira de Zootecnia. 2001; 30(1):1099-1105. http://www.revista.sbz.org.br/artigo/index.php?artigo=2935

26. Conrad HR, Pratt AD, Hibss JDW. Regulation of feed intake in dairy cows. I. Change in importance of physiological factors with increasing in digestibility. Journal of Dairy Science. 1964; 48(1):47-54. http://www. journalofdairyscience.org/article/S0022-0302(64)88581-7/abstract

27. Buxton DR, Russel JR. Lignin constituents and cell wall digestibility of grass and legume stems. Crop Science. 1988; 28(1):553-558. http://dl.sciencesocieties.org/publications/cs/abstracts/28/3/ $\underline{\mathrm{CS} 0280030553 \text { ? access }=0 \& \text { view }=\text { pdf }}$ 